\title{
New regular numeral symbols from one to septillion
}

\author{
Yiren Qin ${ }^{1}$ and Guangrui $\mathrm{CaO}^{2}$ \\ ${ }^{1}$ Black Family Stem Cell Institute, Department of Developmental and Regenerative \\ Biology, Icahn School \\ ${ }^{2} 69$ E 97ST New York
}

June 10, 2021

\begin{abstract}
Some iconic symbols representing numbers are more animated, picturesque, and impressive. Here we describe a kind of new numeral symbols from one to septillion. These symbols are regular and simple. Meanwhile it is easy to write and remember these number symbols. They are composed of 27 basic components. After these basic components are regularly combined, simple and effective numeral symbols from one to septillion can be generated. They might be used in games, movies, animations, computer science and even in other arts.
\end{abstract}

\section{Hosted file}

Manuscript.pdf available at https://authorea.com/users/406146/articles/516922-new-regularnumeral-symbols-from-one-to-septillion 


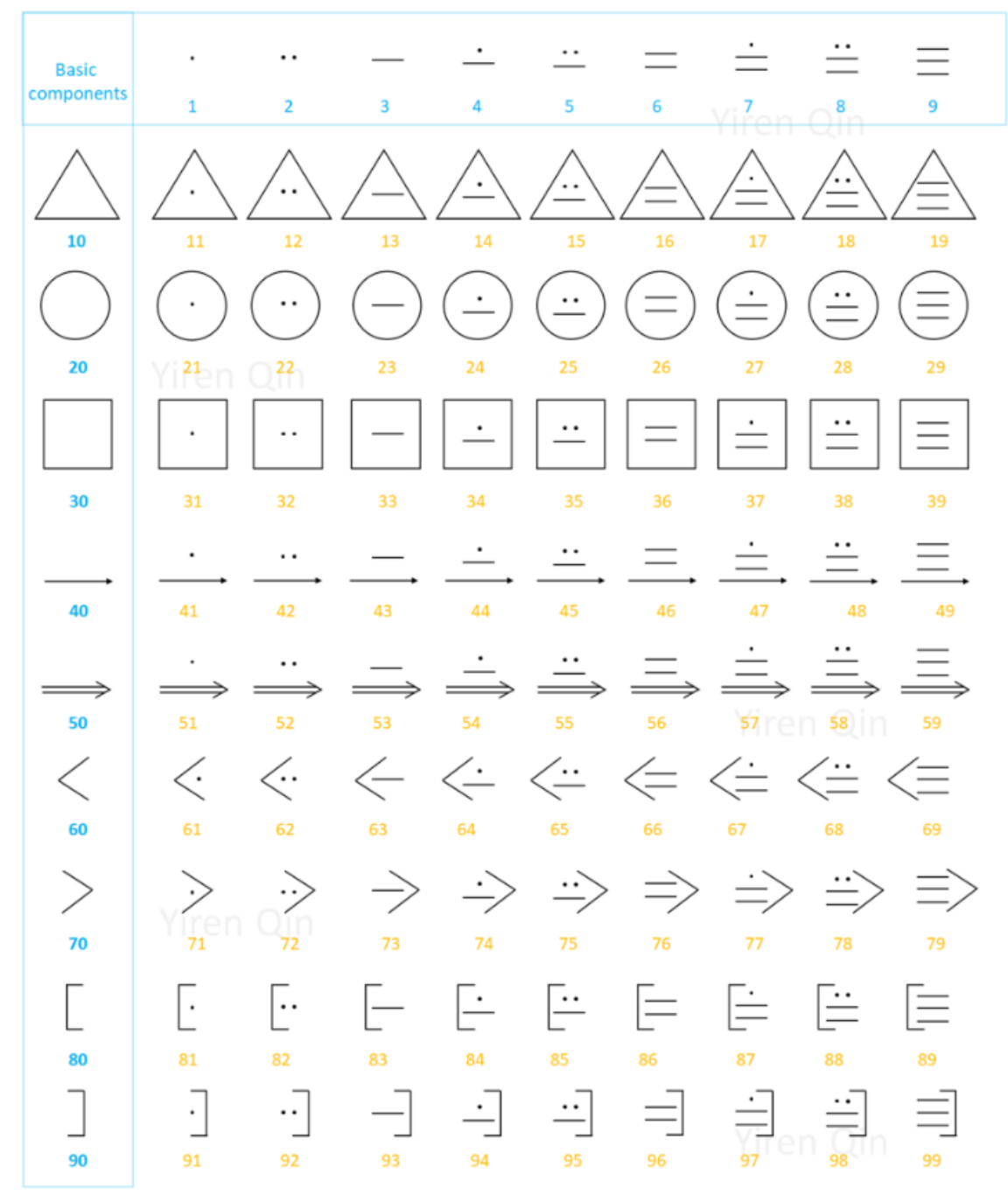

Figure 1: This is a caption 